\title{
経頭蓋的磁気刺激における渦電流の有限要素解析および精神疾患治療のため の至適刺激条件の検討
}

\author{
Numerical Calculation of Eddy Currents in Transcranial Magnetic Stimulation and \\ Optimization of Stimulus Parameters for Psychiatric Treatment \\ 関野正樹・上野照岡川 \\ 東京大学大学院医学系研究科 医用生体工学講座, 東京都文京区本郷 7-3-1 ( ₹ 113-0033) \\ M. Sekino and S. Ueno \\ Department of Biomedical Engineering, Graduate School of Medicine, University of Tokyo, 7-3-1 Hongo, Bunkyo-ku, Tokyo \\ 113-0033, Japan
}

\begin{abstract}
Current distributions in transcranial magnetic stimulation (TMS) were calculated under various conditions and compared with the current distribution in electroconvulsive therapy (ECT) in order to find an optimum condition of TMS as an alternative to ECT. Current distributions in TMS were obtained for the following coil shapes and coil diameters: circular coils of $50 \mathrm{~mm}, 75 \mathrm{~mm}, 100 \mathrm{~mm}, 125 \mathrm{~mm}$, and $150 \mathrm{~mm}$, and figure-eight coils of $50 \mathrm{~mm}, 75 \mathrm{~mm}, 100 \mathrm{~mm}$, and 125 $\mathrm{mm}$. Stimulus parameters in TMS were evaluated using a performance function $\mathrm{F}$ which increases with the difference in the current distributions between ECT and TMS. The minimum value of $\mathrm{F}$ decreased with an increase in the coil diameter. In the case of a $150-\mathrm{mm}$ circular coil, the performance function had a minimum value of $6.3 \mathrm{~A}^{2} / \mathrm{m}^{4}$ at a coil current of $29 \mathrm{kA}$, which corresponded to a magnetic flux density of $0.24 \mathrm{~T}$. A coil position on the forehead and the use of a large circular coil gave better results.
\end{abstract}

Key words: transcranial magnetic stimulation, electroconvulsive therapy, finite element method

\section{1. はじめに}

電気痤攣療法(electroconvulsive therapy：ECT)は, 電流 印加により脳を刺激することで，重篤な精神疾患を改善す る治療法である 1),2). 経頭蓋的磁気刺激 (transcranial magnetic stimulation: TMS)は, 脳にパルス磁場を印加し て発生する渦電流によりニューロンを刺激する手法である 3),4).ECT に代わり TMS を用いることで, 同等の治療効果 をより低侵襲に得られる可能性がある.TMS で精神疾患を 治療する試みは多くなされているにも関わらず 5),6),有効な 結果が得られたという報告はわずかである．我々は有限要 素法により $\mathrm{ECT} と \mathrm{TMS}$ の電流分布を比較し，TMS を用 いて ECT と同等の強さの電流を得られることを示した ${ }^{7)}$. Nadeem らはインピーダンス法により同樣の計算を行い， TMS では ECT に比べて電流がより表面付近に局在するこ とを示した ${ }^{8)}$.

ECT の治療効果には不明な点が多いため, 精神疾患を治 療するという目的に対して, どのような電流分布が望まし いのかについては明らかにされていない．しかし，一つの

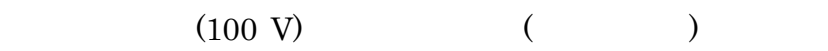
まで多くの治療が成功している．㫕こで，TMSを ECT の 代わりに用いる初期段階の試みとしては，ECT に近い電流
分布を与える条件で TMS を行えば, 少なくとも確実な゙治 療効果を得られると予測できる この仮説に基づいて，我々 は 8 字コイルを用いた TMS の樣々な条件について, ECT との間で脳内電流分布の比較を行い, ECT に近い電流分布 を与えるための, TMS の最適な条件を求めた ${ }^{9)}$.

本研究では, 8 字コイルに加えて，新たに円形コイルを 検討の対象とした.TMSにおいて現在広く使用されている コイル形状は, 円形コイル , 8 字コイル , またはこれらに 多少の変更を加えたコイルである.したがって，8 字コイ ルと円形コイルとの間で電流分布の比較を行うことを主な 目的とした . TMS の樣々なコイル半径やコイル位置, コイ ル電流にて得られる脳内電流分布について, ECT における 脳内電流分布との比較を行い, ECT に近い電流分布を与え るための, TMS の最適な条件を求めた .

\section{2 方法}

計算モデルは Brooks Air Force Laboratory が製作した ヒト頭部の 3 次元モデルを用いた ${ }^{10)}$.このモデルは ,Visible
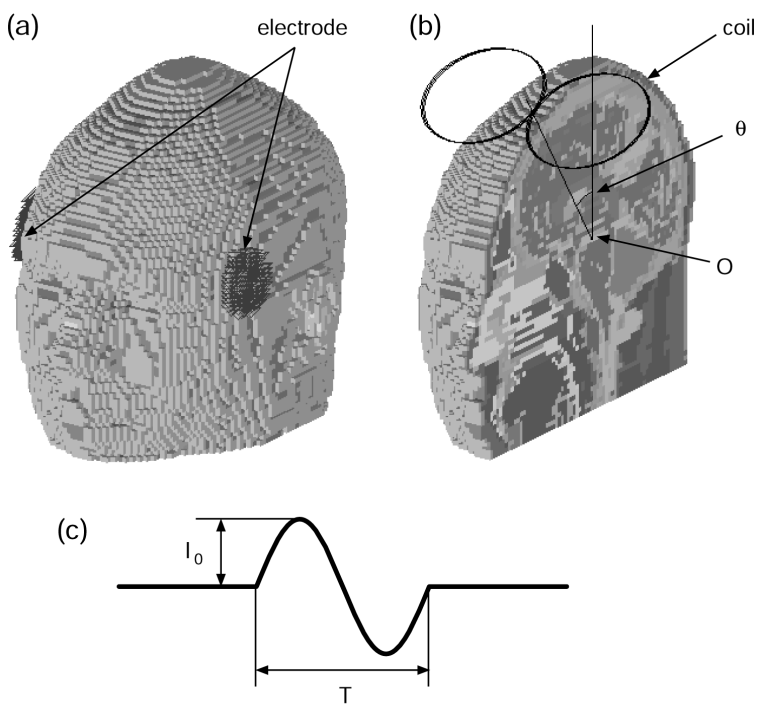

Fig. 1 (a) Numerical model of electroconvulsive therapy (ECT). A voltage of $100 \mathrm{~V}$ was applied between a pair of electrodes located at the tempora. (b) Numerical model of transcranial magnetic stimulation (TMS). Pulsed electric currents were applied to a coil placed on the scalp. (c) Waveform of the coil current in TMS. 
Human Project ${ }^{11)}$ によ得られたスライスデータを , 24 種 類の組織に分類したものである. Gabriel による組織の電 気的特性から ${ }^{12), 13)}$,Cole-Cole モデル ${ }^{14)}$ に基づいて ,50 Hz と $4.2 \mathrm{kHz}$ における導電率を計算し, 关れ光れ ECT の計 算モデルと TMS の計算モデルの各組織に割り当てた . 組 織の比透磁率は, 全て 1.0 とした. 元のデータはボクセル サイズ $1 \mathrm{~mm}$ で作成されたが, 計算量を低減するため, ボ クセルサイズ $3 \mathrm{~mm}$ に再構成した . モデルの節点数および 要素数は，光れ光れ 189975 および 177649 である.計算 は, 株式会社フォトンのソフトウェア Photo Series を用い て行った .

ECT の典型的な条件として，Fig. 1(a)に示すように，両 こめかみに電極を配置し, 電極間に $100 \mathrm{~V}$ の電圧を印加し た．電位は片側 137 個の節点に設定し，これは電極の表面 積約 $13 \mathrm{~cm}^{2}$ に相当する. ECT は $50 \mathrm{~Hz}$ 程度の低周波数で 行われるため,電位 脳内の電位分布を求めた .

$\nabla^{2} \phi=0$.

電極以外の表面に対して，次の境界条件を適用した .

$$
\frac{\partial \phi}{\partial n}=0
$$

ただし $\partial / \partial n$ は境界に垂直な方向の偏微分を表す . ECT に おける電流密度 $\mathrm{j} \mathrm{E}$ を, 電位㠶よひ導電率のから, 次のよう に計算した。

$$
\mathbf{j}_{E}=-\sigma \nabla \phi \text {. }
$$

TMS モデルの刺激コイルとして ,円形コイルと 8 字コイ ルをモデルした . 円形コイルは直径 $50 \mathrm{~mm}, 75 \mathrm{~mm}, 100$ $\mathrm{mm}, 125 \mathrm{~mm}, 150 \mathrm{~mm}$ の 5 種類, 8字コイルは直径 $50 \mathrm{~mm}$, $75 \mathrm{~mm}, 100 \mathrm{~mm}, 125 \mathrm{~mm}$ の 4 種類について計算を実施 した . Fig. 1(b)に, TMS モデルを 75 mm の 8 字コイルと ともに示す．電流のコイル位置への依存性を求めるため, コイルを頭頂から前頭に向けて , 頭部の中心点 $\mathrm{O}$ を中心 角度 $\theta$ 移動させた $\left(\right.$ Fig. $1(b)$ は $\left.\theta=30^{\circ}\right)$. コイルに流れるパル ス電流 $\mathrm{I}(\mathrm{t})$ の波形を Fig. 1(c)に示す .パルス幅を $\mathrm{T}$, 電流の ピーク値を $\mathrm{I}_{0}$ として, $\mathrm{t}=0$ から $\mathrm{t}=\mathrm{T}$ の間では $\mathrm{I}(\mathrm{t})=$ $\mathrm{I}_{0} \sin (2 \pi \mathrm{t} / \mathrm{T})$ と表される.この論文では，T を一定值 $240 \mu \mathrm{s}$ とした .コイルがモデル上の位置 $\mathbf{r}$ に発生する磁場 $\mathrm{B}(\mathbf{r}, \mathrm{t})$ を, Biot-Savart の法則から計算した .

$$
\mathbf{B}(\mathbf{r}, t)=\frac{\mu_{0} I(t)}{4 \pi} \int \frac{\boldsymbol{\tau}\left(\mathbf{r}^{\prime}\right) \times\left(\mathbf{r}-\mathbf{r}^{\prime}\right)}{\left|\mathbf{r}-\mathbf{r}^{\prime}\right|^{3}} d s .
$$

ただし $\mu_{0}$ は真空の透磁率， $\mathrm{I}(\mathrm{t})$ はコイルに流れる電流， $\tau\left(\mathbf{r}^{\prime}\right)$

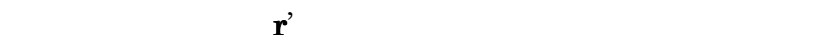
る.式(4)は,コイルの導線を積分経路とする線積分であり，

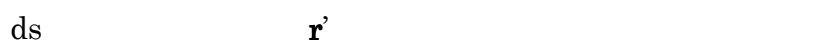
イルの円周を 72 個の要素に分割し 積分を和に置き換えて 実行した . TMS における渦電流密度 $\mathbf{j}_{\mathrm{T}}$ のベクトルポテン シャル廿を，次のように定義した．

$$
\mathbf{j}_{T}=\nabla \times \boldsymbol{\psi} \text {. }
$$

脳内渦電流分布を, 次の式から計算した .

$$
\nabla^{2} \boldsymbol{\psi}=\sigma \frac{\partial \mathbf{B}(\mathbf{r}, t)}{\partial t} .
$$

モデルの表面に対しては, 次の境界条件を適用した .

$$
\boldsymbol{\psi}=\mathbf{0} \text {. }
$$

ECTおよびTMSにおける電流分布の差を評価するため， 次の関数を定義した .

$$
F=\frac{1}{V_{0}} \int_{\text {cerebrum }}\left(\left|\mathbf{j}_{E}\right|-\left|\mathbf{j}_{T}\right|\right)^{2} d V .
$$

ただし $\mathrm{V}_{0}$ は大脳の体積である .積分は大脳全体に対して行 った .この関数は, ECT による電流 $\mathbf{j}_{\mathrm{E}}$ と TMS による電流 j T差とともに増加する . したがって , F を最小にするよ うな TMS の条件を, 最適な刺激条件と考えることができ る.

\section{3. 結果と考察}

Fig. 2(a)(b)(c)に，ECT における電流分布を coronal， sagittal , transversal の各断面について示す . モデルの両 こめかみに置いた電極の縁にあたる表面で, 電流密度が大

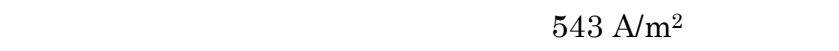
頭蓋は他の組織に比べて導電率が小さいため，印加された 電流のうち，大部分か顗皮を伝わって電極間を流れた．両 電極か漓隹れているため, 電流は脳全体に分布し, 脳の深部 にもある程度到達した . 脳中心部の白質組織において 5 $\mathrm{A} / \mathrm{m}^{2}$ 程度の電流密度を示した Fig. $2(\mathrm{~d})$ に脳(灰白質, 白質, 小脳)表面上の電流分布を示す．電極に近い前頭葉で, 電流 が大きな值を示した . 脳内における電流密度の最大值は 22 $\mathrm{A} / \mathrm{m}^{2}$ であった .

Fig. 3(a)(b)(c)に, TMS における電流分布を coronal , sagittal ,transversal の各断面について示す.コイルは 100 $\mathrm{mm}$ の円形コイルを使用し , コイルの頭頂からの角度は $\theta=$ $60^{\circ}$, コイルへの印加電流は $45 \mathrm{kA}$ である . Fig. 3(d)に , 脳
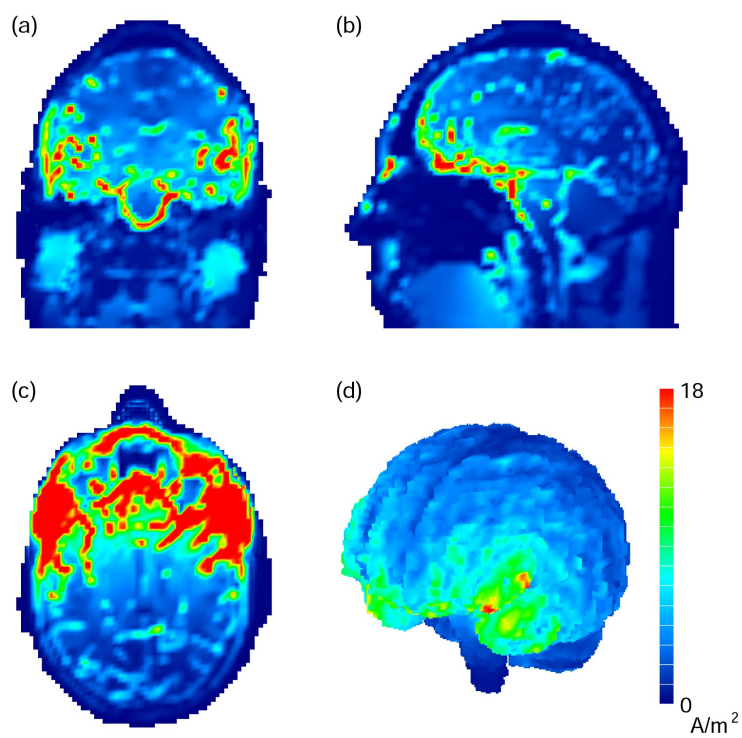

Fig. 2 Current distributions in ECT represented in (a) coronal, (b) sagittal, and (c) transversal slices, and (d) the brain surface. 

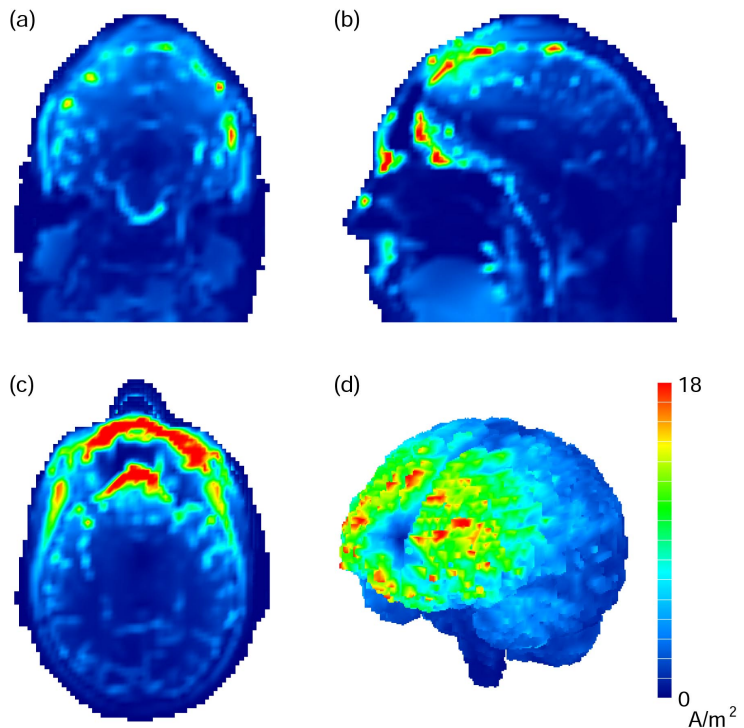

Fig. 3 Current distributions in TMS by a $100-\mathrm{mm}$ circular coil represented in (a) coronal, (b) sagittal, and (c) transversal slices, and (d) the brain surface.

表面の電流分布を示す . Fig. 4(a)(b)(c)に，75 mm の 8 字 コイルを用いたTMSにおける電流分布を coronal, sagittal， transversalの各断面について示す.コイルの頭頂からの角 度は $\theta=60^{\circ}$, 印加電流は $45 \mathrm{kA}$ である . Fig. $4(\mathrm{~d})$ に , 脳表 面の電流分布を示す .8 字コイルの交差部直下の表面では， 2 つのコイル要素が同じ方向に渦電流を誘導するため, 渦 電流は交差部直下に集中した．したがって，コイル直下の 脳表面で, 大きな電流密度を示した. 円形コイルでは, 8 字コイルに比べてより広い範囲に電流が分布した . 脳内の 最大電流密度は円形コイルの場合に $26 \mathrm{~A} / \mathrm{m}^{2}, 8$ 字コイル の場合に $27 \mathrm{~A} / \mathrm{m}^{2}$ であり，ECT と同程度の值が得られた． 組織の比透磁率が一樣であるため，コイルから発生した磁 場は妨げられることなく脳へ達し，脳内に渦電流を誘導す る．したがって，頭皮に大きな電流が流れることはない． 頭部モデル全体に対する電流密度の最大值は, 円形コイル の場合に $53 \mathrm{~A} / \mathrm{m}^{2}, 8$ 字コイルの場合に $64 \mathrm{~A} / \mathrm{m}^{2}$ であった . コイルが発生する磁場は, コイルからの距離とともに減衰 する．したがって，渦電流はコイルに近いモデル表面で大 きく，表面からの深さとともに減少する．脳の中心部にお ける電流密度は $2 \mathrm{~A} / \mathrm{m}^{2}$ 以下であり，これは ECT の場合に くらべて小さい .コイルの半径が小さ場合には, 渦電流 がより小さな領域に局在し，脳深部における渦電流の減衰 効果もより顕著にあらわれる.Fig. 1(b)に示したように , 2 つのコイル要素を水平に配置したため, 側頭に近い領域に もある程度の渦電流が流れた .

Fig. 5 に, 評価関数 $\mathrm{F}$ のコイル電流およびコイル位置へ の依存性を示す 図の(a)と(b)では光れ光れ直径 $100 \mathrm{~mm}$ の 円形コイルと直径 $75 \mathrm{~mm}$ の 8 字コイルを使用し，頭頂か らのコイルの角度 $\theta$ を $0^{\circ}$ から $60^{\circ}$ まで变化させた . TMS に より誘導される渦電流 jтはコイル電流に比例する．したが つて評価関数 $\mathrm{F}$ を式(8)のように定義した場合， $\mathrm{F}$ は放物線
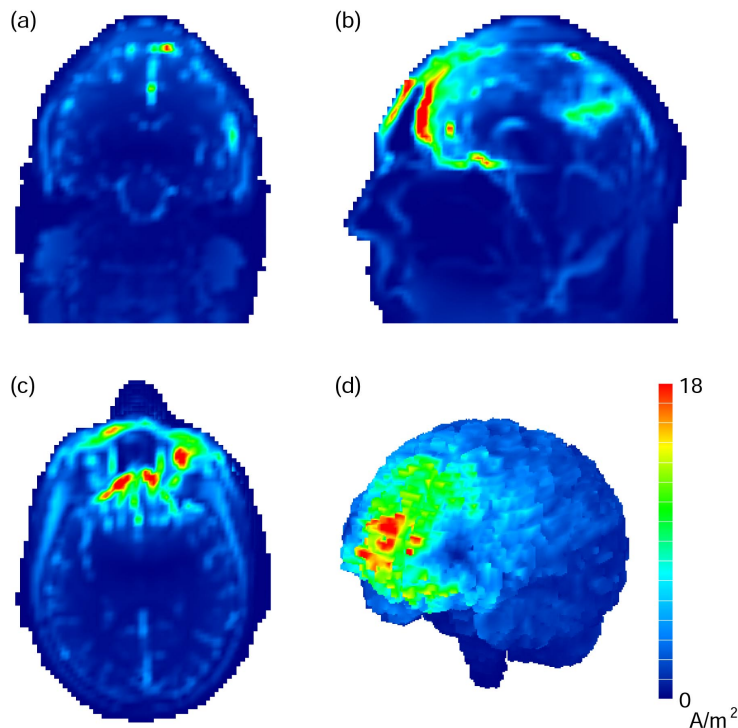

Fig. 4 Current distributions in TMS by a $75-\mathrm{mm}$ figure-eight coil represented in (a) coronal, (b) sagittal, and (c) transversal slices, and (d) the brain surface.
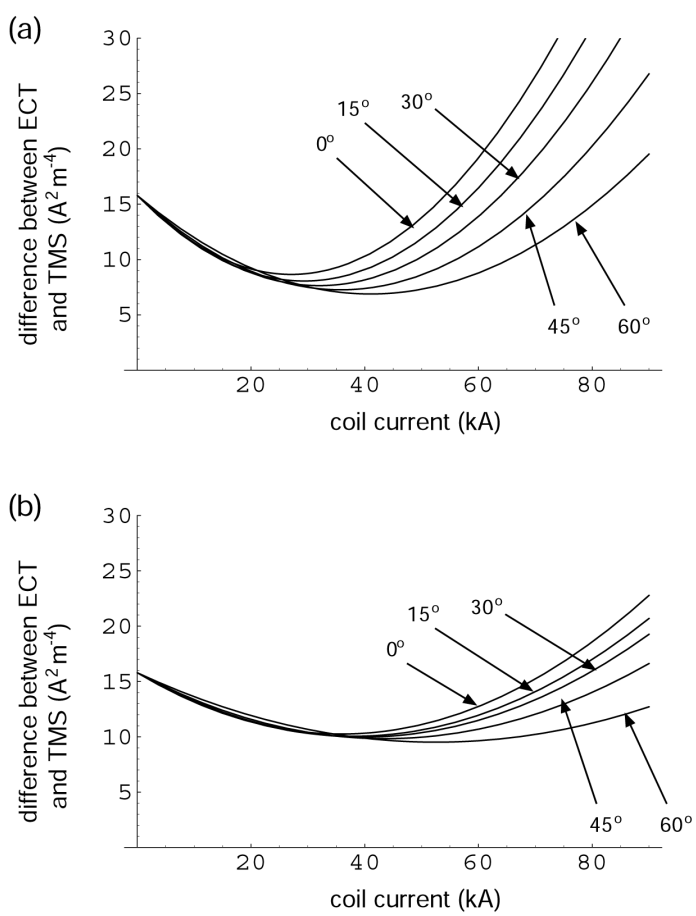

Fig. 5 Dependence of the performance function $F$ (equation (8)) on the coil current and the coil position for (a) circular coils and (b) figure-eight coils. The coil position is represented by angle $\theta$ from the vertex.

となる . F の最小值は, 角度 $\theta$ の増加とともに減少した .こ れは ECT の電極をこめかみに置いたため, コイルが $\theta$ の増 加とともに電極位置へ接近し, 前頭に大きな電流が流れた ためである．我々が以前に行った計算では TMS のコイル を頭頂に置いたが 7)，今回の計算から，コイルを前頭に置 いた方が ECT に近い電流分布を得られることが分かる.今 回の計算では , コイルと鼻との干渉を避けるために , $\theta$ の範 

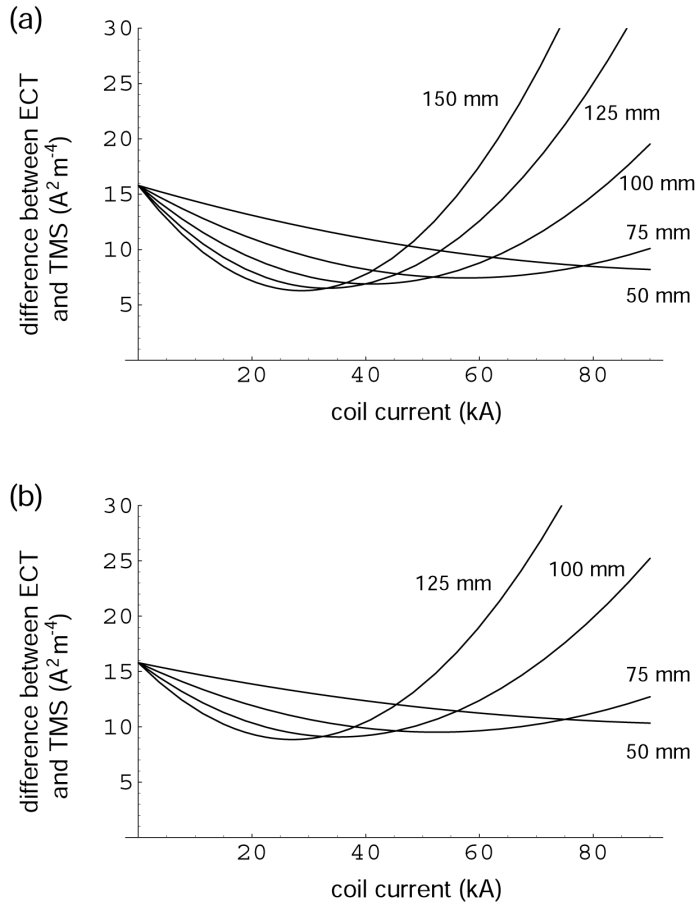

Fig. 6 Dependence of the performance function $\mathrm{F}$ on the coil current and the coil diameter for (a) circular coils and (b) figure-eight coils.

囲を $60^{\circ}$ までに制限した。円形コイルの場合， $\theta=60^{\circ}$ ，コ イル電流 $41 \mathrm{kA}$ に対して $\mathrm{F}$ の最小值 $6.9 \mathrm{~A}^{2} / \mathrm{m}^{4}$ が得られた . このとき ,コイル要素の中心における磁場は $0.52 \mathrm{~T}$ となる . 8 字コイルの場合, $\theta=60^{\circ}$, コイル電流 $53 \mathrm{kA}$ に対して $\mathrm{F}$ の最小値 $9.5 \mathrm{~A}^{2} / \mathrm{m}^{4}$ が得られた . $\mathrm{F}$ の最小值を与えるコイル 電流は, 角度 $\theta$ の増加とともに減少した .これは, 角度 $\theta$ 代 小さい場合，頭頂に流れる電流が $\mathrm{F}$ の増加を招くことによ る。

Fig. 6 に, 評価関数 $\mathrm{F}$ のコイル電流およびコイルの直径 への依存性を示す．頭頂からの角度は $60^{\circ}$ に固定し，図(a) では直径 $50 \mathrm{~mm}, 75 \mathrm{~mm}, 100 \mathrm{~mm}, 125 \mathrm{~mm}, 150 \mathrm{~mm}$ の円形コイルについて, 図(b)では直径 $50 \mathrm{~mm}, 75 \mathrm{~mm}$, $100 \mathrm{~mm}, 125 \mathrm{~mm}$ の 8 字コイルについて計算を行った . F の最小值は，コイルの直径の増加とともに減少した .これ は, コイルが大きいほど渦電流が広範囲に分布し，また電 流がより深部まで達するためである。したがって，ECTに 近い電流分布を得るためには, 大きなコイルを用いること か望ましい、今回計算したコイルの中では, 直径 $150 \mathrm{~mm}$ の円形コイルが最も良い結果を与えた . 直径 $150 \mathrm{~mm}$ の円 形コイルの場合, コイル電流 $29 \mathrm{kA}$ に対して $\mathrm{F}$ の最小值 $6.3 \mathrm{~A}^{2} / \mathrm{m}^{4}$ が得られた . このとき, コイル要素の中心におけ る磁場は $0.24 \mathrm{~T}$ となる. 異なる直径のコイルに対して , F の值はあまり大きく変化しなかったのに対して，F の最小 値を与えるコイル電流は大きく変化した . したがって , 大 きさの異なるコイルを用いる場合には，コイル電流を慎重 に選択する必要がある.F の最小值を与えるコイル電流は， コイルの直径の増加とともに減少した .これは, 等しいコ
イル電流に対して, 直径の大きなコイルの方が側頭により 大きな電流が流れるためである .

ECT では $50 \mathrm{~Hz}$ の電流か加えられるのに対して，TMS では実効的な周波数 $4.2 \mathrm{kHz}$ の電流力加えられる. 電流密 度が等しくても, このように周波数が異なれば, ニューロ ンに与える刺激の効果が必ずしも等しいとは限らない . 例 えばニューロンが興奮するための刺激電流の強さ (strength)と電流パルスの幅(duration)との関係，すなわち strength-duration curve が, 多くの先行研究から明らかに されている . ヒトの脳において，興奮閾値に対応する電流 の強さは, duration が約 $2 \mathrm{~ms}$ より長い範囲ではほぼ一定 であり，興奮閾値が光の一定值の 2 倍となる duration，す なわち chronaxie は, 約 $0.1 \mathrm{~ms}$ である ${ }^{15)}$. この值は矩形 パルス電流に対して得られたものであり，TMSゃ ECT と は波形の点で異なるが, ここでは粗い近似として, この値 を乥のまま用いて考察する．ECT の実効的なパルス幅は $20 \mathrm{~ms}$ であり，TMS のパルス幅は $0.24 \mathrm{~ms}$ である.これら のパルス幅に対して, strength-duration curve から興奮閾 值を求めると，TMS のパルス幅における興奮閾値は，ECT の実効的なパルス幅における興奮閾值に比べて $30 \%$ 程度 大きいことが示される.したがって，周波数の相違を考慮 した場合には,コイル電流 $38 \mathrm{kA}$, 磁場の強さ $0.31 \mathrm{~T} に て$ TMS を行うことか望ましい .

本論文では，現在広く使われている TMS の装置を用い て実現可能な範囲内で,ECTに最も近い電流分布を得るた めの刺激条件を求めた .コイルの形状を円形と 8 字に限定 したため，最適化された TMS の刺激条件においても，な お ECT との間に電流分布の相違か認められる.コイルの形 状をより一般化して，例えば 8 字コイルを構成する 2 つの 円形コイル要素の間にある程度の距離を設けることや， 2 つ以上の円形コイルを同時に使用することを許容してシミ ユレーションを行えば, ECT にさらに近い電流分布を得ら れる可能性がある，乥れでも非接触の TMS を用いて ECT とほとんど変わらない電流分布を得ることは, 電磁気学的 な観点からも困難である . 本論文の結果を臨床に応用する にあたっては，本論文において求められた最適な刺激条件 は，乥れを用いて ECT と等しい治療効果が得られることを 保証するものではなく，現行の磁気刺激装置を用いて可能 な範囲で最も ECT に近い電流分布を与えるものであると いう点に, 留意する必要がある。

本論文では式(8)を評価関数として定義した . 別の評価関 数を定義すれば, 導かれる結論も変わり得るため, どのよ うな評価関数を選ゔべきかという問題は, 本質的に重要で ある、現状では，ECT が治療効果を発揮するメカニズムが ほとんど明らかにされていないため，脳のどの領域に電流 を与えることが必要なのか, ECT の研究者の間でも統一し た見解が得られていない 将来的に ECT のメカニズムや作 用点が明らかになれば，治療すべき局在点において十分な 電流を与え, 光れ以外の領域では電流密度がほとんどゼ口 になるような電流分布か理想であり，光のような電流分布 
を基準にして評価関数を設定したときに，真に最適な刺激 条件を求めることができる.

\section{4. まとめ}

本研究では, 有限要素法を用いた数值解析にもとづいて， ECT に近い電流分布を与えるような TMS の刺激条件を求 めた . 結論として, 刺激コイルの位置は頭頂より前頭部に 置く方か望ましく, また直径 $150 \mathrm{~mm}$ 程度の大きな円形コ イルを用いる場合に望ましい結果が得られることが分かっ た .

謝辞 本研究は財団法人磁気健康科学研究振興財団ならび に文部科学省科学研究費補助金特別推進研究 (No. 12002002), 日本学術振興会特別研究員奨励費の援助によ った.

\section{References}

1) American Psychiatric Association: Task Force on Electroconvulsive Therapy: The Practice of Electroconvulsive Therapy: Recommendations for Treatment, Training, and Privileging, 2nd ed. (American Psychiatric Association, Washington, DC, 2001).
2) R. Abrams, Electroconvulsive Therapy, 3rd ed. (Oxford University Press, New York, 1997).

3) A. T. Barker, R. Jalinous, and I. L. Freeston: Lancet, 2, 1106 (1985).

4) S. Ueno, T. Matsuda, and M. Fujiki: IEEE Trans. Magn., 26, 1539 (1990).

5) M. S. George, E. M. Wassermann, W. A. Williams, A. Callahan, T. A. Ketter, P. Basser, M. Hallett, and R. M. Post: Neuroreport, 6, 1853 (1995).

6) T. A. Kimbrell, J. T. Little, R. T. Dunn, M. A. Frye, B. D. Greenberg, E. M. Wassermann, J. D. Repella, A. L. Danielson, M. W. Willis, B. E. Benson, A. M. Speer, E. Osuch, M. S. George, and R. M. Post: Biol. Psychiat., 46, 1603 (1999).

7) M. Sekino and S. Ueno: J. Appl. Phys., 91, 8730 (2002).

8) M. Nadeem, T. Thorlin, O. P. Gandhi, and M. Persson: IEEE Trans. Biomed. Eng., 50, 900 (2003).

9) M. Sekino and S. Ueno: IEEE Trans. Magn., 40, 2167 (2004). 10) www.brooks.af.mil/AFRL/HED/hedr/dosimetry.html

11) www.nlm.nih.gov/research/visible/visible_human.html

12) C. Gabriel, S. Gabriel, and E. Corthout: Phys. Med. Biol., 41, 2231 (1996).

13) S. Gabriel, R. W. Lau, and C. Gabriel: Phys. Med. Biol., 41, 2251 (1996).

14) K. S. Cole and R. H. Cole: J. Chem. Phys., 9, 341 (1941).

15) J. Holsheimer, E. A. Dijkstra, H. Demeulemeester, and B. Nuttin: J. Neurosci. Methods, 97, 45 (2000).

2004 年 10 月 7 日受理, 2005 年 3 月 15 日採録 